\title{
ALTERIDAD, POÉTICA Y FILOSOFÍA EN LA OBRA DE ANTONIO MACHADO
}

\author{
MARÍA RODRÍGUEZ GARCÍA \\ Universidad Pablo de Olavide (Sevilla)
}

\begin{abstract}
RESUMEN: La obra de Antonio Machado muestra una conocida amplitud temática que se manifiesta, además de en su poética, en sus aportaciones a la filosofía. El presente artículo pretende acercarse a su figura desde la conjunción entre la poética y la filosofía en base a un concepto fundamental en su obra: la alteridad. Como consecuencia de la quiebra de la razón moderna, el solipsismo de corte cartesiano quedó en suspenso. Es en este momento en el que tanto en Europa como en la España de finales del siglo XIX surge una tendencia hacia la alteridad o reconocimiento del otro, tal y como veremos en la obra de Machado y en personajes esenciales de su producción como Juan de Mairena así como, también, en otros autores de la generación del 98.
\end{abstract}

PALABRAS CLAVE: poética; filosofía; literatura; Antonio Machado; pensamiento español.

\section{Otherness, Poetics and Philosophy in the work of Antonio Machado}

ABSTRACT: Antonio Machado's work shows a well-known thematic breath that is manifest, besides its poetical legacy, besides in its poetical legacy, in its contributions to Philosophy. This article tries to approach his figure from the conjunction between Poetics and Philosophy, based on a fundamental concept in his work: the otherness. As a result of the breaking of modern reason, Cartesian solipsism was called into question. Is in this time, the late 19th Century, a trend towards the otherness or recognition of the other arises in Europe as in Spain, and we see it in the work of Machado, especially in his character Juan de Mairena, and also in others authors of 98's generation.

KEY WORDS: poetry; philosophy; literature; Antonio Machado; spanish thinking.

\section{INTRODUCCIÓN}

El legado poético y narrativo de Antonio Machado es incuestionable, un legado que está plagado de una clara influencia filosófica que no podemos eludir y que nos permite asignarle, además, el rol de «filósofo». Dicha preocupación por el sentido de la realidad emerge en un contexto histórico-cultural problemático, siendo dicha circunstancia uno de los gérmenes esenciales de su producción literario-filosófica.

La conocida como crisis del 98, fruto de las pérdidas coloniales producidas como consecuencia de la Guerra de Cuba, supuso un antes y un después en el ánimo y en el desarrollo de la sociedad española. Si bien es cierto que los orígenes de esta crisis se pueden remontar a la época del regeneracionismo, no fue hasta las pérdidas coloniales cuando se agudizó el espíritu crítico de una generación que reclamaba una nueva sensibilidad y marco hermenéutico ante la cambiante realidad. Es pertinente apuntar, además, que los metarrelatos científicos al modo de la modernidad ya habían dejado de surtir efecto, lo cual originó una disconformidad en el ser humano que ya no se conformaba con saberse perteneciente a un universo descifrable según la terminología lógicocalculante. Ya decía Machado, en 1915, que: 
«El racionalismo cartesiano tuvo, en las postrimerías del siglo XVIII, su conversión popular al absurdo en el culto de la Diosa Razón (...) La razón se hace mística o agnóstica, todo menos racional, y ya no vuelve a levantar cabeza ${ }^{1}$.

Es esta falta de legitimidad de una razón sesgada uno de los motivos esenciales que produjeron la inestable situación finisecular. El periodo de crisis que comenzó a partir de la segunda mitad del siglo XIX y que desembocó en la necesidad de nuevos modelos hermenéuticos, precisaba otras respuestas, otros paradigmas que se hicieran eco del contexto histórico-cultural emergente de esa crisis.

Una de las respuestas ante tal situación devastadora fue la adopción de los principios vitalistas-existenciales que, años antes, habían sido desarrollados por filósofos europeos como Friedrich Nietzsche, Sören Kierkegaard y, más recientemente, Henri Bergson. Esta tendencia fue adoptada por los autores de la generación del 98 que, imbuidos del espíritu problemático de su tiempo, acogieron los principios europeos como propios en tanto que participaban de un contexto común.

En el presente artículo desgranaremos a qué se refiere la conjunción entre la literatura y la filosofía que emergió en España a raíz de la generación del 98. Dichos nexos los analizaremos en función de la filosofía de Antonio Machado y su aportación más importante: la alteridad. Al mismo tiempo, analizaremos cómo dicho concepto es paradigmático en una generación que huía de la omnímoda razón moderna y que pretendía afianzar el declive de los metarrelatos modernos. En este punto nos detendremos en cuatro de las principales obras literarias de principios del siglo XX que contribuyen a la conformación de la nueva filosofía española. Nos referimos a las conocidas como «novelas de $1902 »^{2}$, cuatro obras en las que sus autores (Miguel de Unamuno, Ramón del Valle-Inclán, Pío Baroja y Azorín) recogen el espíritu problemático de la España de la época e inauguran la nueva filosofía española, la misma que se imbuye de los principios del pensamiento europeo. Lejos de complejos y herméticos sistemas, el pensamiento español se encuentra integrado en todos los aspectos de la cultura y en la vida de los hombres. La filosofía española bebe de la literatura de su tiempo, pues la palabra narrada también se ha hecho eco de los problemas filosóficos que ocupaban a la Europa de la época. Como ejemplo de ello podemos apuntar las aventuras de Don Quijote, quien nos acerca a la problemática de la escisión entre la ficción y la realidad, la subjetividad del tiempo

\footnotetext{
1 Machado, A., Los complementarios. Madrid, Ediciones Cátedra, 1996, p. 126.

2 Las «novelas de 1902» supusieron la renovación de la novelística española de principios de siglo. Se trata de cuatro novelas que dejan atrás el modelo realista de tiempos pretéritos y que buscan ahondar en la decadencia del alma humana, el desengaño y la apatía existencial producidas por un contexto histórico cuanto menos problemático. Dichas novelas son: Amor y pedagogía, de Miguel de Unamuno, Camino de perfección, de Pío Baroja, Sonata de otoño, de Ramón del Valle-Inclán y La voluntad, de Azorín.
} 
así como el problema de la razón moderna. Y este paradigma filosófico es el que propiamente caracteriza a los pensadores de fin de siglo.

De este modo, pretendemos adentrarnos en la filosofía española de principios del siglo XX, destacando su componente literario así como su caracterización como pharmakon para afrontar una delirante realidad marcada por la crisis de la modernidad europea y la crisis finisecular.

\section{La alteridad: Filosofía y literatura en Antonio Machado}

La exposición de la poética y, consecuentemente, de la filosofía de Antonio Machado es a través de Juan de Mairena, apócrifo del autor y protagonista de uno de sus libros más conocidos. «Poeta, filósofo, retórico e inventor de una máquina de cantar ${ }^{3}$, Mairena vive durante la segunda mitad del siglo XIX y muere en 1909.

La poética machadiana es contraria al pensamiento lógico y se entrega a la vida, entregándose a la temporalidad humana y desbordando los límites de la poesía del intelecto, abstracta, intemporal e incapaz de dar voz al alma humana. Frente al pensamiento lógico, que tiende a un pensar homogéneo de la realidad, Machado nos muestra el pensamiento poético como vía de descubrimiento del cambio, de lo otro que yo, de la heterogeneidad del ser (esto es, la alteridad, la existencia como conciencia).

El canto del poeta es la palabra de la diferencia, de la creación de mundo. Es la palabra que da voz a la nada y se pregunta por el ser, origen de la metafísica y de la poesía. Pero Machado no se queda sólo en las postrimerías de la poética. Su exposición va más allá de los propios límites de la poesía y nos habla de la lógica poética, una de sus más innovadoras propuestas.

La lógica poética es la expresión de la vuelta a la intimidad que supone la poesía y, a la vez, un nuevo modo de razonamiento que tiene en cuenta la necesidad de ahondar en la heterogeneidad del ser. Si bien es cierto que para Machado el razonamiento era, a veces, culpable de la aniquilación de la emoción ante el asombro, no es menos cierto que, al mismo tiempo, abogaba por una razón humana basada en el diálogo. Mediante este intercambio de palabras, Machado apuesta por una lógica o razonamiento que tenga en cuenta lo uno y lo otro, lo diferente y que es ajeno al propio yo. La lógica poética de Machado tiene en cuenta la importancia de la forma, pero debido al ineludible nexo con la poesía, centra su interés en la comprensión de la realidad desde múltiples perspectivas. La nueva poética machadiana es concebida como intento de relegar la lógica tradicional a la categoría de artificio, pues carece de sentido común al afanarse en construir razonamientos ajenos al propio discurrir del tiempo.

3 Machado, A., Poesías completas. Madrid, Espasa Calpe, 2007, p. 344. 
El pensar poético ofrece una profunda perspectiva hermenéutica que permite ahondar en el fundamento, en la esencia, en la angustia que se origina en la conciencia del hombre que es incapaz de aprehender al otro. Es la angustia de saberse solo y a la vez acompañado, la angustia ante la nada. De este modo, podemos afirmar que la poética machadiana nos ofrece una perspectiva de comprensión de la realidad en la que la problemática relación entre el ser y la nada es piedra angular en la misión y creación del poeta. Éste debe superar esa nada para revelar la heterogeneidad del ser, trascendiendo todo pensar lógicoconceptual y siendo voz de su tiempo, pues es éste en su dimensión existencial algo propio del hombre.

Frente a la palabra de la lógica, anclada en sus leyes y sus abstracciones, la lógica poética nos ofrece una perspectiva de comprensión de la realidad que va más allá de la verdad del ente. Se ocupa, por el contrario, del devenir de lo real y de la irremediable sucesión del tiempo.

Sólo desde el punto de vista de la lógica poética es posible ahondar en la comprensión de la heterogeneidad del ser y del pensar. De este modo, se comprende la existencia como conciencia, así como temporalidad que anhela superar su finitud. Estas cuestiones, esencialmente humanas, son definitorias de la poética machadiana, paradigma de comprensión de lo real que el poeta pone en boca, fundamentalmente, de Juan de Mairena, portavoz de su filosofía. Y es que, nuestro mundo es, como apunta Mairena, esencialmente apócrifo, «un poema de nuestro pensar» ${ }^{4}$ heterogéneo, poético e inmerso en la temporalidad del ser.

\section{Perspectivas de la alteridad en la filosofía de Antonio Machado}

La percepción del mundo enunciada por Mairena, («poema de nuestro pensar»), se encuentra afectado por el tiempo, por un contexto que le pertenece y que determina el pensamiento del hombre. De este modo, el devenir histórico pasa a ser el escenario en el que se crea ese mundo, ese poema que emerge de la conciencia de los hombres ${ }^{5}$.

La creación de mundo a la que nos remite Machado parte de su intento de superación del subjetivismo del siglo XIX. Si el siglo XVII se caracterizaba por el dominio de la razón (mediante una defensa de que nuestro conocimiento no recae directamente sobre la realidad, sino sobre la idea que de ella tenemos);

\footnotetext{
4 Machado, A., Juan de Mairena I. Madrid, Cátedra, 2009, p. 195.

5 La referencia al devenir histórico y a la posibilidad de que el hombre se desarrolle en la historia nos recuerda a Hegel, quien hablaba del despliegue de la historia como el escenario en el que el hombre se desenvuelve en un proceso dialéctico complejo que consta de una tríada: tesis, antítesis y síntesis, siendo en este último momento en el que se produce el completo desarrollo de la conciencia del hombre así como las manifestaciones de la misma.
} 
el XVIII, siguiendo a Nietzsche ${ }^{6}$, es aquel que está dominado por los apetitos superficiales que se embriagan del libertinaje y disfrute social de los hombres, un siglo en el que parecía que la realidad se encontraba sometida a la sentimentalidad. Frente a estos dos modos (aparentemente contrapuestos) de comprender el mundo, nos encontramos con el siglo XIX, que a los ojos del pensador alemán se muestra como más animal, realista, «ni temeroso ni considerado con la "razón", ni con el "corazón"; profundamente convencido de la supremacía de los instintos» ${ }^{7}$.

El idealismo alemán, desarrollado entre finales del siglo XVIII y comienzos del XIX, trabaja la emergencia del yo como actividad que cuenta en sí misma con su propio principio. La tesis idealista comprende al sujeto como el absoluto, algo que implica la creación de una teoría metafísica del ser y del fundamento en la cual el sujeto ostenta el papel principal. Por todo ello, podemos afirmar cómo el idealismo alemán se sitúa más allá de la comprensión del sujeto como correlato del objeto en la experiencia, siendo la realidad el absoluto en el que el sujeto encuentra su propio fundamento, más allá del cogito (recordemos a este respecto la importancia que tuvo dicha conceptualización en Descartes) como principio gnoseológico. La subjetividad empieza ahora a ser pensada en términos dialécticos (hecho que nos remite directamente a Hegel y su concepción dialéctica de la realidad y del conocimiento) y que otorga un papel característico y determinante al yo: es necesario acoger un «yo» que se conciba como fundador del ser de las cosas como ideas propias, pues sólo de este modo nos es posible acceder a lo real. Por tanto, la corriente subjetivista que se desarrolla en el siglo XIX presenta una clara militancia contra el predominio onto-gnoseológico del objeto. La realidad se define desde la individualidad, la cual confiere una interpretación de las cosas.

Este mismo siglo, cuya tendencia al vitalismo (como superación de la razón moderna y del sentimentalismo del siglo XVIII) es incuestionable, no está exento del dogma científico, ese que intenta ofrecer una respuesta nítida a cualquier interrogante. Al mismo tiempo, se muestra preso de la herencia de la Ilustración, que asocia la liberación espiritual de los hombres al hallazgo del conocimiento sólidamente fundado y de validez universal. Y ese dogma heredado cumplió su proceso de transformación en el positivismo, un modelo de conocimiento que se encuentra fundado en la observación de los fenómenos, en la comparación y la inducción que, mediante leyes empíricas trata de penetrar en todos los puntos de la vida del hombre. De este modo, la vida humana queda reducida a una sucesión fenoménica no exenta de ser contrastada por leyes que ofrecen respuestas de toda índole (ya sean de calado político, social, moral, científico o filosófico).

6 Nietzsche, F., La voluntad de poder. Madrid, Edaf, 2007, p. 92, Expresa aquí Nietzsche las diferencias entre los siglos XVII, XVIII y XIX.

7 Ibidem, p. 93. 
Si bien Nietzsche elogió la dimensión cientificista del siglo XIX, lo hizo como réplica a la actitud idealista que envolvía la comprensión de la existencia humana para ir más allá de la religión, de la metafísica y de la moral. Pero ello no supone que toda la expresión positivista fuera para el filósofo alemán algo digno de alabanza: el objetivismo que rozaba el fetichismo y la valoración de los hechos frente a las interpretaciones fueron dos de los pilares positivistas atacados por Nietzsche, para quien no es tan creíble un sistema puramente objetivo cuanto uno filtrado por las diferentes interpretaciones de los fenómenos de lo real, podría decirse, un sistema de calado positivista.

Pues bien, es en la crítica al subjetivismo donde podemos encontrar el origen de la teoría de la alteridad de Machado. Desde ella, se reconoce al otro como alternativa a la supremacía de la subjetividad que, anteriormente, nos aferraba a la conciencia solipsista. Al mismo tiempo, la aspiración a la trascendencia a la que nos referimos es uno de los elementos a los que podemos referirnos para hablar de superación de la modernidad y su exacerbada razón solipsista. Y es que, el hombre no es un ser aislado e indiferente al mundo que le rodea, al contrario. Tal y como en su día dijera Aristóteles, el hombre es el zoon politikon, un animal social que, por ello, necesita estar en comunidad, en comunión con los demás.

La posibilidad de existencia de la conciencia de la alteridad, se relaciona directamente con el pensar poético. El reconocimiento del otro en Machado surge en el momento en que somos conscientes de no poder aprehender en primera persona al otro que yo. En ese momento, la heterogeneidad del ser se nos revela como una conciencia diferente a nuestro propio "yo». Este descubrimiento abierto a la conciencia queda impregnado por la angustia y la soledad que embriaga al hombre quien, irremediablemente, tiende al otro y siente la necesidad de él. Es así como se gesta la angustia que le invade y que se comprueba en el saberse perteneciente a un mundo abismático en el que, además, no es posible encontrar suelo firme ni consuelo para su anhelo. Por lo tanto, si asumimos la hipótesis de la heterogeneidad del ser, nos vemos abocados a una honda problematización de la racionalidad, pues como afirma el propio Machado en Los complementarios:

«Objetividad no es ya nada positivo: es simplemente el reverso borroso y desteñido del ser. Sólo existen, realmente, conciencias individuales, conciencias varias y únicas, integrales e inconmensurables entre sí. Sólo es común a todas las conciencias el trabajo de desubjetivización, la actividad homogeneizadora, creadora de esas dos negociaciones en que las conciencias coinciden: tiempo y espacio, bases del lenguaje y del pensamiento racional» ${ }^{8}$.

En dicho texto, de 1923, podemos comprobar cómo se apuesta por la individualidad de los hombres que son, a su vez, conscientes de la existencia de otros «yo» ajenos a su propio sí mismo. En este punto nos encontramos con la

8 Machado, A., «Sobre la objetividad». En Los complementarios. Madrid, Cátedra, 1996, pp. $145-146$. 
heterogeneidad de las conciencias, que, coincidiendo en un espacio y tiempo, son miembros de una comunidad implícita en el carácter de las conciencias heterogéneas.

La conciencia de la radical heterogeneidad del ser es comprensible desde la lógica poética de Antonio Machado. La voz del poeta se presenta como un claro exponente de la capacidad ejecutiva del arte: mediante la creación de mundo, a partir de la palabra, el poeta es capaz de responder al abismo de su tiempo concreto. Y es este pensar poético el que nos permite comprender que

«La realidad es una potencia ciega, acéfala; poco podremos con fundamento decir de ella, por cuanto ella es lo primero, lo elemental e indefinible. Lo creador del mundo de la representación, del sueño búdico en que vivimos sumergidos. Nuestra representación no podrá servirnos —si pensamos lógicamente- para penetrar en lo real» ${ }^{9}$.

El pensar poético nos hace, por tanto, ser conscientes y partícipes de la alteridad: frente a lo defendido por el pensamiento lógico tradicional, la poética machadiana comprende el carácter heterogéneo del ser, así como de lo real. Es este punto, por tanto, esencial para reconocer la cercanía de este pensamiento a la cuestión de la alteridad, pues se trata de aprehender el mundo desde la divergencia, desde una perspectiva que rechaza lo homogéneo y atiende a la diferencia, a la creación fuera de los límites trazados por la dimensión óntica. La realidad se aprehende desde un conocer cuyos paradigmas han sido metamorfoseados: es posible alcanzar un pensamiento certero de la realidad más allá del mero cogito, de ese sujeto pensante que duda de todo excepto del hecho de estar pensando.

La poesía puede entenderse, entonces, como un relato de la "colectiva individualidad» de los hombres, reconociéndose así la necesaria existencia de ese otro que participa del ser individuo al igual que cada yo, que a su vez se conforma desde su ser otro.

Desde la perspectiva machadiana es posible abogar por una comprensión de la alteridad desde la palabra poética. Ello se lleva a cabo mediante la palabra, herramienta que trata de aprehender una realidad que se resiste a ser desposeída de sus metáforas. La lógica poética aboga por la alteridad, por la existencia de conciencias heterogéneas que implican el reconocimiento de la fraternidad entre los hombres. Es esta tendencia a la comunidad (desde una perspectiva espiritual) un claro rechazo a la manifestación de la individualidad al modo del idealismo racionalista que encuentra, además, justificación en el concepto de pueblo como arquetipo de comprensión de la fraternidad humana.

\subsection{Pueblo y comunidad espiritual}

El concepto de pueblo tiene un denso trasfondo histórico filosófico. Ya los románticos hablaron de Volksgeist o espíritu del pueblo como nexo de unión entre la identidad de cada hombre y la colectiva. Dicho argumento nos lleva

$9 \quad$ Ibidem, p. 88. 
a suponer un trasfondo espiritual que, más allá de una sucesión acumulativa de individualidades, hace del pueblo una especie de organismo vivo en el que destaca la importancia y la necesidad de unión entre los hombres, los mismos que conservan su propia identidad dentro del Volksgeist. La comunidad de individuos en que se conforma el espíritu del pueblo implica una acción conjunta en la que, lejos de perder su individualidad, se concentran en una pluralidad de voces que nos llevan a comprender y experimentar la existencia del otro que yo. El Volksgeist hará referencia desde un sentido espiritual a la comunidad de hombres que, lejos de perder su propia individualidad, se saben pertenecientes a una pluralidad que les otorga una voz común que contempla, a la vez, la multiplicidad entre las culturas.

La comprensión espiritual de los pueblos también llegará a España. Si bien a finales del siglo XIX la emergencia de los nacionalismos así como los estudios antropológicos de la época comenzaron a ocuparse de ello, es a partir de los años veinte cuando se produjo un creciente interés por la explicación del pueblo desde ese trasfondo espiritual que en su día fue acuñado por los románticos. En el caso de Machado, la importancia concedida al alma popular venía influenciada, en parte, pos su padre, Antonio Machado Álvarez, conocido como Demófilo, apasionado del folclore así como del estudio antropológico de los pueblos.

En el caso de Antonio Machado, el poeta, la expresión de la conciencia del pueblo será el reconocimiento de la alteridad, siendo de ahí de donde surge la necesidad de desarrollar, como bien indica José Luis Abellán ${ }^{10}$, una investigación sobre el sentir común popular, capaz de atender a lo que Machado denominó como «tú esencial». Este estudio podrá ser llevado a cabo desde lo que se conoce como "poesía comunista», expresión de la exaltación de la palabra poética en consonancia con el sentir del alma popular, aquella que se hace eco del folclore popular y respecto a lo que añade Machado que:

«Lo esencial humano se encuentra con la mayor pureza y el más acusado relieve en el alma popular. Mi folclore no ha traspuesto las fronteras de mi patria. Pero me atrevo a asegurar que, en España, el prejuicio aristocrático, el de escribir exclusivamente para los mejores, puede aceptarse y aún convertirse en norma literaria, sólo con esta advertencia: la aristocracia española está en el pueblo, escribiendo para el pueblo se escribe para los mejores» ${ }^{11}$.

\section{El ReCurso de lo apócrifo y la trascendencia en el Pensamiento de Machado}

La necesidad de apelar a la existencia del otro es una constante en el pensamiento filosófico de Machado así como en su producción literaria. Como ya hemos apuntado, la heterogeneidad del ser responde a la angustia que se nos

10 Abellán, J. L., «La elaboración de pueblo como categoría cultural». En su libro El filósofo Antonio Machado. Valencia, Pre-textos, 1995, pp. 107-121.

11 Machado, A., Juan de Mairena II. (1936-1938), Madrid, Ediciones Cátedra, 2004, p. 61. 
revela al ser conscientes de nuestra incapacidad de aprehender la individualidad ajena. Es entonces cuando, ante la necesidad de poseer o hacernos partícipes de la existencia del otro, somos conscientes de su existencia y de hasta qué punto ésta nos constituye.

En un intento por superar el pensamiento homogéneo, Machado inventa una serie de personajes, los apócrifos, que se convierten en los profetas de su filosofía. El origen etimológico de la propia palabra «apócrifo» nos lleva a traducirla como lo oculto, lo secreto, lo fingido. Machado supone la existencia de estos hombres, desvela la necesidad que de ellos (en tanto que otredades) se tiene para la creación de mundo. Al mismo tiempo, la creación de personajes apócrifos supone dar paso a lo oculto, a la angustia que se nos revela ante la necesidad del otro. Es el reconocimiento de la esencial heterogeneidad del ser. Machado llega aún más lejos al afirmar que vivimos en un mundo esencialmente apócrifo, inventado y desgarrado de su ser oculto, donde

«Lo apócrifo de nuestro mundo se prueba por la existencia de la lógica, por la necesidad de poner el pensamiento de acuerdo consigo mismo, de forzarlo, en cierto modo, a que sólo vea lo supuesto o puesto por él, con exclusión de todo lo demás» ${ }^{12}$.

Lo apócrifo se convierte en la necesidad de superación del pensar homogéneo, de reconocer el carácter dramático de la existencia: la vida humana es un continuo ejercicio de creación. Somos nosotros los que inventamos y escribimos nuestra existencia, autores de nuestra propia acción, del drama existencial en el que estamos inmersos. Necesitamos y, a la vez, queremos ser otro, y esto es algo defendido por Machado, para quien esta necesidad imperiosa es lo específicamente humano, pues «su mónada solitaria no es nunca pensada como autosuficiente, sino como nostálgica de lo otro, paciente de una incurable alteridad $»^{13}$.

Es esencialmente humana la concepción de un pensamiento trascendente, producto de la nostalgia del otro, de la «esencial disconformidad consigo mismo que lo impulse a desear ser otro del que es» ${ }^{14}$. Y es que, para Machado, el deseo de ser otro no sólo guarda relación con el anhelo de poseer o ser partícipes de la existencia ajena, sino que la alteridad queda también explicada en querer ser otro, experimentar desde un punto de vista nostálgico la posibilidad metafísica de otra identidad. Ello es también un reconocimiento del otro que yo y de la necesidad de trascender los propios límites de la conciencia individual. A este respecto se pronuncia Machado al reconocer que «sólo el pensamiento del hombre, a juzgar por su misma conducta, ha alcanzado esa categoría supralógica del deber ser o tener que ser lo que no se es» ${ }^{15}$. Y es en este contexto

\footnotetext{
12 Machado, A., Juan de Mairena I., op. cit. (nota 4) p. 195.

13 Ibidem, p. 323.

14 Ibidem, p. 323.

15 Ibidem, p. 324.
} 
en el cual la imaginación juega un papel fundamental: el hombre crea, inventa mundo y también a sus personajes, pues, tal y como reconoce Machado,

«¿Quién nos aseguraría que la realidad descubierta no era otro velo, destinado a rasgarse a su vez y a descubrirnos otro y otro?... Dicho de otra forma: la ilusión de lo ilusorio del mundo podría siempre acompañarnos dentro del más real de todos los mundos (...) El mundo como ilusión y el mundo como realidad son igualmente indemostrables» ${ }^{16}$.

El recurso de lo apócrifo es expresión de una doble vertiente de calado metafísico: por una parte responde a la angustia existencial que se nos revela al reconocer la imposibilidad de aprehender la existencia del otro que yo, una existencia que, sustancialmente, se nos presentaba como oculta. Al mismo tiempo, esta teoría machadiana guarda una estrecha relación con la propuesta de Unamuno acerca del «yo ex-futuro (las posibilidades de ser que tuvimos pero no fuimos)». Al igual que sucediera con el apócrifo machadiano en cuanto a dimensión dramática de la existencia, Unamuno nos presenta la posibilidad de pensar en la alteridad desde aquellas extensiones propias del yo que no fuimos pero que pudimos llegar a ser. Es la teorización de la pregunta acerca de qué hubiera sido de cualquiera de nosotros si hubiésemos optado por otro camino distinto al que nos encontramos. Pero esto lo veremos, con más detenimiento, en el siguiente apartado.

4. La CUEstión de la alteridad en la generación del 98: Unamuno, Azorín, BaRoJa y VALLE-INCLÁN

El reconocimiento del otro que yo se planteó, para los autores de la generación del 98, como una alternativa a la razón omnímoda moderna, la misma que inducía al hombre a un estado de aislamiento perceptible en la filosofía de la época (recordemos al respecto el ego cogito cartesiano o las mónadas leibnizianas, prototipos de razón autosuficiente que ignora el reconocimiento efectivo de algo más que el propio pensamiento). Ya hemos visto cómo para Antonio Machado la alteridad guardaba una estrecha relación con la esencial heterogeneidad del ser (necesitamos algo diferente y externo a nosotros) así como con el recurso del apócrifo (la realidad se crea a partir de personajes que, al mismo tiempo, nos proporcionan una otredad necesaria), conceptos que nos alejan del solipsismo moderno y nos introducen en un nuevo contexto histórico y de pensamiento. Además de Machado, otros autores de la generación del 98 encajan a la perfección en este nuevo perfil mediante su contribución a la creación de un nuevo modelo literario y filosófico en la España de comienzos del siglo XX. Lejos de tratarse de una mera renovación de géneros, la propuesta de estos autores se encamina a definir y expresar lo que Ortega y Gasset denominaría

$16 \quad$ Ibídem, p. 358. 
como el «problema de España» o enfermedad de la conciencia nacional apresada en sus deficiencias históricas.

Los autores a los que nos referimos contribuyen, al igual que Machado, a la creación de una nueva conciencia colectiva en la que la importancia del otro que yo se torna esencial. Nos referimos a Unamuno, Azorín, Baroja y Valle-Inclán, autores esenciales en la conformación del nuevo pensamiento y la nueva literatura en España.

\subsection{La alteridad en las novelas de 1902}

En el caso de Unamuno y su teoría del «yo ex-futuro» a la que nos referimos con anterioridad, el tratamiento que se ofrece de la alteridad es desde un punto de vista individual, es decir, responde a las otras posibilidades de existencia desde un punto de vista propio. La propuesta de Unamuno nos presenta una dimensión de la alteridad que avala la afirmación de la consistencia dramática de la vida, pues se postula, incluso, la posibilidad de ser otro: «y esta, mi vida, ¿es novela, es nivola o qué es? Todo esto que me pasa y que les pasa a los que me rodean, ¿'es realidad o ficción?» ${ }^{17}$.

La vida desde un punto de vista creativo es una constante en el pensamiento de Unamuno, hasta el punto de, como vemos a partir de este texto de Niebla, cuestionarse cuál sea la verdadera existencia, qué pertenece al ámbito de la realidad y de la ficción. Otro de los textos de Unamuno que asienta su preocupación por la alteridad es Amor y pedagogía, novela publicada en 1902 y una de las imprescindibles en lo que hemos llamado como nueva filosofía y nueva literatura de principios del siglo XX. Amor y pedagogía ofrece una reflexión sobre el género novelesco y, personalmente, responde a un momento crítico del autor ${ }^{18}$. Preocupado por el destino de la ciencia, Unamuno ya expresa en el propio título de la obra su necesidad de salvarse personalmente lejos de creencias absolutamente racionales. Ahora es el turno de apostar por ese «hombre de carne y hueso» al que se referirá directamente años más tarde, en Del sentimiento trágico de la vida.

Amor y pedagogía es una sátira respecto a la labor de la ciencia y la pedagogía que, para el autor vasco, quedaban completamente separadas de la vida y de la individualidad humana. Avito Carrascal, su protagonista, está obsesionado con la razón y el progreso, lo que le hace pensar en todos los ámbitos de su vida desde dicha perspectiva. Así, por ejemplo, busca esposa en base a un método deductivo que, supuestamente, también es efectivo para elegir a la madre perfecta para su futuro hijo perfecto. Todo está perfectamente estudiado: el nombre del hijo, sus costumbres, gustos y educación en pro de una

17 Unamuno, M., Niebla, Madrid, Alianza, 2003, p. 164.

18 La redacción de Amor y pedagogía se comprende como un desahogo por parte del autor, quien en 1897 había sufrido una aguda crisis personal que se acompaña de la desilusión que experimenta respecto al progreso y al socialismo. 
vida racionalmente modélica. Hasta la casa de Avito Carrascal y de Marina, su esposa, está provista para recibir al hijo:

«La casa está dignamente provista para recibirlo; techos altos, como ahora se lleva, iluminación, aireación, antiseptia. Por todas partes barómetros, termómetros, pluviómetro, aerómetro, dinamómetro, mapas, diagramas, telescopio, microscopio, espectroscopio, que a donde quiera que vuelva los ojos se empape en ciencia; la casa es un microcosmos racional ${ }^{19}$.

Pero la realidad abarca mucho más que lo que una metodología pueda apresar, y Avito descubrirá pronto que no todo es tan fácil ni tan cuadriculado. La propia historia planteada nos muestra cómo la metodología científica no puede captar todo ápice de realidad con sus métodos. Dicho efecto también se capta mediante la propia estructura de la novela que, abierta y de corte improvisado y vitalista nos muestra un discurso que fluye y que se presenta como alternativa al logos tradicional. Al mismo tiempo, los personajes están en constante lucha entre su mundo interior y lo que se encuentra en el mundo externo. Los personajes buscan en el otro su propio yo, algo que nos acerca a la preocupación por la alteridad, ello se cifra también en el protagonismo que cobran los diálogos, es decir, el intercambio de experiencias entre un yo y el otro. Al mismo tiempo, la problemática relación entre el mundo interior y el exterior es otro modo de acercarse a la heterogeneidad del ser, que diría Machado. No somos seres aislados, sino que necesitamos de otro que yo que se cifra, además, en un complejo y amplio contexto ajeno a nosotros pero que, a la vez, nos pertenece. Un mundo que, para Avito es un gran caleidoscopio ${ }^{20}$, cambiante y plural.

La alteridad para Unamuno es un elemento esencial para mostrar su desilusión ante el progreso y la ciencia. Mediante el contacto con el otro, mediante el amor, el hombre recupera el sentido de la vida y se hace cargo de sí mismo, de su propio ser de carne y hueso. La alteridad unamuniana plantea una perspectiva trágica a la par que vitalista sobre la realidad de su tiempo y el lugar que ocupa el hombre. Algo similar ocurrirá en las obras de los otros autores mencionados, también protagonistas de la renovación de la novela en 1902.

José Martínez Ruíz -Azorín - es conocido por dicho pseudónimo a partir de 1904, adoptando así el nombre del personaje homónimo de La voluntad. Dicha novela, de 1902, es una de las obras esenciales para comprender el nacimiento de la novela filosófica en España a comienzos del siglo XX así como uno de los enclaves de análisis de la alteridad.

La obra rompe con los esquemas de la novela realista, siguiendo así los parámetros de las novelas de 1902 que nos ocupan. Es posible que dicha obra de Azorín tenga su inspiración en las famosas Cartas a Hamlet de Clarín, donde el autor lamenta que en España no se cultiva la novela filosófica como sí ocurría, por ejemplo, en Francia.

19 Unamuno, M., Amor y pedagogía. Madrid, Alianza, 2000, p. 61.

20 Íbidem, p. 113. 
Al igual que sucede con el resto de novelas de 1902, La voluntad es un ejercicio de metaliteratura que tiene al diálogo como uno de sus principales protagonistas. Es precisamente dicha circunstancia la que le concede naturalidad a la obra y la que hace de la misma un referente en cuanto a la propuesta de alteridad se refiere. En este sentido, el lenguaje popular se convierte en un aliado, pues es una muestra del sentir del pueblo que redunda en la emergencia de una nueva literatura filosófica. Estos diálogos cobran especial importancia entre el personaje de Azorín y Yuste, su maestro. Ambos tienen una relación de maestro-discípulo que nos recuerda a la formación pedagógica propuesta por el Bildungsroman o novela de formación pedagógica en la que se muestra el aprendizaje vital de los personajes. Dicha relación entre el maestro y su discípulo es una clara muestra de la alteridad, de la preocupación y ocupación por el otro así como su destino. La voluntad muestra a un Azorín que anhela buscarse a sí mismo fuera de las fronteras de Yecla, un pueblo anclado en sus tradiciones y en el que la religión se presenta desde una doble vertiente: como búsqueda de consuelo y como dominio. La vida en Yecla se percibe como dolor, como repetición constante, y Azorín decide emprender un viaje que será, además, una oportunidad para descubrirse a sí mismo. Pero no hay salvación posible. La redención buscada por Azorín pasa por aceptar la otredad más inmediata de su familia, su pueblo y sus tradiciones. Nos encontramos ante una alteridad que no siempre se nos ofrece como la alternativa más positiva en la relación entre el hombre y su entorno, no así como nos la ofreciera Machado. En el caso de Valle-Inclán y Baroja la situación es parecida, aunque, al igual que sucediera con Unamuno muestran un nexo de esperanza respecto al otro que nos hace ver que no siempre está todo perdido.

Ramón del Valle-Inclán es otro de los autores emblemáticos de la generación del 98. En lo referente a las novelas de 1902 que señalamos, Valle-Inclán escribió Sonata de otoño, que forma parte de un compendio de novelas (Sonata de estío, de 1903, Sonata de primavera, de 1904, y Sonata de invierno, de 1905) cortas pero no por ello no elaboradas que, si bien pueden ser leídas de forma independiente, contempla un núcleo interno que las hace interdependientes. Dichas novelas suponen un ejercicio de ironía en el que Valle-Inclán cuestiona los tópicos del simbolismo y del decadentismo europeo, tendencias en boga en la época y que constituyen uno de los principales ejes narrativos para los intelectuales españoles de finales del siglo XIX.

Sonata de otoño, de 1902, es un ejercicio de metaliteratura mediante el cual cuestiona los principios del modernismo literario: la perfección en la forma, la mezcla de intelectualismo y sexualidad, la compleja relación entre el espíritu y la carne... Tópicos que Valle-Inclán reproduce en la relación entre el Marqués de Bradomín y Concha, su amada enferma que parece estar en completa simbiosis con el decadente otoño gallego. La relación entre ambos se percibe como muestra de una alteridad que se difumina, además, con el paisaje así como con el autor. El mundo de la Sonata de otoño se entiende como un despliegue imaginario en el que se funden narrador, autor y personajes principales, formando el narrador un bucle de anécdotas que difuminan los límites entre la realidad y 
la ficción. En el fondo, nos encontramos ante una aplicación de la técnica del esperpento de Valle-Inclán, esto es, la crítica y la sátira contra la España oficial, chabacana y mentirosa en pro de un hombre de carne y hueso renovado. El mundo que nos presenta Valle-Inclán en la Sonata parece una construcción imaginaria que gira en torno a la figura de Bradomín y Concha. Es decir, parece ese "poema de nuestro pensar» al que aludiera Machado. Dicha elaboración, de corte apócrifo, es una muestra de la alteridad a la que nos referimos y que se manifiesta en la interacción entre los personajes y el paisaje, algo que también sucede en la historia que nos plantea Pío Baroja.

Camino de perfección es el título de la obra de Baroja que forma parte del compendio de las novelas de 1902. Su protagonista principal es Fernando Ossorio, un joven estudiante de medicina que, hastiado de su vida y su entorno decide emprender un viaje personal en aras de recuperar su yo interior. El camino que emprende Ossorio es similar al de Azorín en La voluntad: una suerte de Bildungsroman en la que el personaje principal sale al mundo exterior para acceder a su yo más íntimo. Al igual que en el caso de La voluntad, la obra de Baroja nos presenta a un personaje complejo que desarrolla su interioridad mediante su interacción con el entorno, una alteridad que se hace eficiente, también, mediante el arte. Y es que, el arte es para Ossorio un claro reflejo de la vida, de la necesidad de reconocerse en el otro. El arte es también un elemento esencial en Machado, quien aludía a una capacidad de ejecución del arte como creación e invención de mundo, una realidad que supone reconocer lo externo a nosotros, otro que yo esencial y necesario que fue reconocido, como hemos visto, por otros autores de la generación del 98.

\section{CONCLUSIÓN}

La crisis de la razón moderna nos ha conducido a la búsqueda de la alteridad, de esa esencial heterogeneidad del ser a la que aludiera Machado y que también se reflejó en otros autores de la generación del 98. El presente trabajo muestra el reflejo del descrédito de la razón omnímoda en la elaboración de una nueva filosofía y una nueva literatura.

Machado nos presenta otro y un yo que están inmersos en un diálogo constante que nos hace cómplices de la comprensión del mundo como "poema de nuestro pensar». Algo similar sucede en la obra de Unamuno expuesta, Amor y pedagogía, donde el yo queda impregnado del otro, el monólogo es diálogo y lo propio se deviene ajeno. Lo real se contempla así, como expresión de lo heterogéneo y manifestación de la contradicción. Así, como dijera Unamuno,

Yo necesito discutir, sin discusión no vivo y sin contradicción, y cuando no hay fuera de mí quien me discuta y contradiga, invento dentro de mí quien lo haga. Mis monólogos son diálogos ${ }^{21}$.

21 Unamuno, Niebla, op. cit. (nota 17), pp. 256-257. 
Las obras expuestas de Azorín, Valle-Inclán y Baroja son también un claro exponente de la nueva actitud que se adoptó en España con motivo de la crisis finisecular. Dicha crisis, además de tener sus consecuencias políticas, sociales y culturales, tuvo una gran repercusión en el ánimo popular, lo que supuso la emergencia de una nueva actitud ante la vida que se corresponde con la realidad y el ánimo europeo del momento. La búsqueda y el reconocimiento del otro se plantean como alternativa al constreñido solipsismo al que nos desembocó la razón moderna que todo justificaba, siendo los autores del 98 los precursores en España de la asunción del fracaso y del error como connatural al hombre de carne y hueso.

\section{BibliografíA}

Abellán, J. L. (1995). «La elaboración de pueblo como categoría cultural». En: El filósofo Antonio Machado. Valencia: Pre-textos.

Machado, A. (1996). «Sobre la objetividad». En Los complementarios. Madrid: Cátedra. Machado, A. (2009). Juan de Mairena I. Madrid: Cátedra.

Machado, A. (2004). Juan de Mairena II. (1936-1938). Madrid: Ediciones Cátedra.

Machado, A. (1996). Los complementarios. Madrid: Cátedra.

Machado, A. (2007). Poesías completas. Madrid: Espasa Calpe.

Nietzsche, F. (2007). La voluntad de poder. Madrid: Edaf.

Unamuno, M. (2000). Amor y pedagogía. Madrid: Alianza.

Unamuno, M. (2003). Niebla. Madrid: Alianza.

Universidad Pablo Olavide

Dpto. Geografía, Historia y Filosofía

MARÍA RodRÍGUEz GaRcía mrodgar2@upo.es

[Artículo aprobado para publicación en enero de 2018] 